\title{
A UTILIZAÇÃO DA INTERNET COMO FERRAMENTA INDISPENSÁVEL NA BUSCA CONTEMPORÂNEA DE INFORMAÇÃO: ALGUNS ASPECTOS RELEVANTES
}

\author{
Dulce Baptista
}

\begin{abstract}
Resumo
A partir da contextualização da Internet como recurso revolucionário no mundo globalizado de hoje, o presente artigo explora sua utilização como ferramenta indispensável na busca da informação destinada à pesquisa, seja esta para fins acadêmicos, científicos, práticos, individuais, comerciais, políticos ou outros. Analisa-se a distinção entre busca e pesquisa, com base em estudo sobre a evolução da rede e dos motores de busca. Considera-se a ética como critério de pesquisa, tendo em vista a facilidade de se acessar, baixar e reproduzir os mais variados documentos a partir da rede. Enfoca-se também o papel do bibliotecário como profissional da informação, diante dos desafios trazidos pela tecnologia e pela explosão da informação.
\end{abstract}

\section{Palavras-Chave}

Internet; Globalização; Pesquisa na Internet; Busca na Internet; Ética; Profissional da informação

\section{INTRODUÇÃO}

A onipresença da informação, viabilizada tanto pela mídia convencional como pela Internet, constitui, como se sabe, uma das grandes características do mundo globalizado dos dias de hoje.
Para o bem e para o mal, o mundo tornou-se pequeno, na medida em que fatos ocorridos em qualquer ponto do planeta são imediatamente registrados e transmitidos por todos os meios. No caso da Internet, essa infovia que rompeu limites, e que, 
além do mais, interage com as pessoas (via consultas, perguntas, grupos de discussão, bate-papo) novos paradigmas foram introduzidos dentro do paradigma maior da informação: 1) ubiqüidade (numa só tarde pode-se estar no Piauí e no Havaí pela rede); 2) sincronicidade (notícias e diálogos em tempo real).

É evidente que ao se falar de usuário da Internet, estamos nos referindo às camadas da população que a ela têm acesso no mundo inteiro, sabendo-se que o acesso ou não à rede constitui por si só um fator de exclusão no dito mundo globalizado. Esse aspecto, entretanto, foge ao escopo do presente artigo. $O$ que interessa, no caso, é explorar a questão da utilização da Internet como ferramenta indispensável na busca da informação destinada à pesquisa, seja esta para fins acadêmicos, científicos, práticos, individuais, comerciais, políticos, organizacionais ou governamentais.

Essa enumeração parte da constatação óbvia de que hoje em dia não há praticamente nenhum tipo de pesquisa que prescinda da Internet, seja para a simples obtenção de dados pontuais, seja no estágio inicial do levantamento bibliográfico, da exploração do assunto em pauta, da troca de idéias com grupos afins, e assim por diante.

Por outro lado, diante do volume exponencial de informação que é incluído diariamente na rede, do caráter predomi- nantemente comercial e/ou superficial dos conteúdos, da proliferação de páginas pessoais, de fontes e, por conseguinte, do fenômeno sempre presente da explosão da informação, aquele que precisa encontrar um dado ou informação específica se vê muitas vezes perdido diante do caos virtual até que consiga encontrar o que the interessa, ou mesmo um ponto de partida para aquilo que deseja pesquisar. A esse respeito, vale mencionar o estudo de Eppler e Mengis (2004), para os quais a Internet é apontada, entre outros fatores, como uma das causas da sobrecarga da informação.

A pesquisa acadêmica, por sua vez, tem trabalhado seus próprios mecanismos de organizar a informação de seu interesse, face ao imperativo crescente de disponibilizar e promover o compartilhamento de textos integrais entre pares, e em qualquer tempo. Como exemplo atual e revolucionário desse tipo de trabalho, mencionem-se os repositórios digitais, os quais requerem, para sua construção, a obediência a uma série de critérios específicos, notadamente à questão da cessão dos direitos autorais. O que se observa é que, independentemente da consulta a repositórios, a bases de dados e mesmo às fontes impressas, o pesquisador, bem como os demais usuários da informação prosseguem fazendo uso cotidiano da Internet, onde, diga-se de passagem, parece haver se cristalizado a 
impressão de que se encontra, quando menos, o caminho das pedras.

Diferentemente, porém, do que ocorre quando manuseia um livro, que constitui um suporte físico unitário de informação, o pesquisador se depara com uma variedade imensa de referências, conteúdos e links que the são disponibilizados pela lógica associativa do hipertexto, em contraste com a leitura linear da fonte impressa. $O$ que se observa então é que, paralelamente à vantagem indiscutível do acesso simultâneo a múltiplos dados e textos que de outra forma poderiam estar inacessíveis, surge o desafio da auto-organização e do estabelecimento do foco em meio a toda a diversidade, relevância/irrelevância, atualidade/obsolescência, repetição e duplicação existente na rede.

Em outras palavras, da mesma forma que facilita enormemente $o$ trabalho de pesquisa, a Internet desafia a capacidade de concentração e de delimitação do assunto a ser pesquisado, tendo em vista que, por mais exaustiva que se pretenda, toda pesquisa não será mais do que um recorte na realidade.

Levando em conta esse cenário, aliado ainda à diversidade e ao surgimento contínuo de novos temas e áreas de interesse, o presente artigo discute alguns aspectos relevantes da pesquisa na rede, tais como a diferença entre busca e pesquisa, ética em pesquisa, e o papel do profissio- nal da informação e das bibliotecas diante dos desafios da atualidade. Apresenta, a título de exemplificação, alguns resultados selecionados a partir de um levantamento realizado no Google sobre pesquisa na Internet.

\section{UMA DIFERENCIAÇÃO IMPORTANTE}

Parece oportuna a referência a Novak (2006), que estabelece uma diferença interessante entre busca (search) e pesquisa (research) na Internet. Segundo ele, com a atividade de busca, o que se põe em prática é o entendimento de tecnologias e motores de busca. Já a pesquisa constitui ciência de biblioteca, no sentido de que agimos conforme o entendimento de como a informação é organizada. Trata-se, portanto, de duas abordagens distintas. Ao traçar uma evolução gradual nas formas de se encontrar informação pela Internet, ele identifica uma mudança de processos - da busca para a pesquisa, ou, segundo ele, de ciência da computação (computer science) para ciência de biblioteca (library science). Para ilustrar, considera, por exemplo, como se julga a qualidade da informação baseada na rede. Inicialmente, havia uma tendência a se avaliar a qualidade com base no domínio: pontogov versus pontocom. Ainda hoje, algumas orientações sugerem que tal avaliação se faça com base na presença de uma cláusula de direito autoral e data. "O autor é identifica- 
do no artigo? Os links funcionam? A ortografia está correta?"

Felizmente, ainda segundo Novak (2006), houve progresso. Agora se observam contexto, formato e fonte. Quem escreveu o artigo - e se houver nomes, o que mais escreveram (o que se encontra mediante simples busca). Faz-se uma avaliação do autor e editor com base em outros títulos publicados. A partir de uma série de constatações, observa que os benefícios relativos da ciência da computação serão eclipsados por uma compreensão de que a pesquisa na Internet se refere antes a se encontrar a informação do que propriamente a buscá-la - e encontrar informação está intimamente relacionado à ciência de biblioteca. É possível que essa visão das coisas peque por um certo maniqueísmo, na medida em que opõe - ou hierarquiza atividades ou funções que na realidade são complementares, e não excludentes.

O que parece claro, em todo caso, é que não é possível recuperar-se a informação com a eficiência e a celeridade que se pretende hoje em dia, sem dispor-se da tecnologia adequada, e essa é propiciada pela ciência da computação. Por outro lado, as habilidades inerentes à pesquisa na rede envolvem, sem dúvida, a combinação ótima dos recursos tecnológicos com os conhecimentos próprios da biblioteca.

\section{A ÉTICA COMO CRTÉRIO DE PESQUISA NA INTERNET}

A partir da distinção mencionada no tópico anterior, a percepção de como a informação é organizada na rede passa a demandar critérios que orientem a pesquisa, tais como: verificação de autoridade - e portanto confiabilidade, veracidade, exatidão e atualidade das páginas exibidas na tela. São critérios práticos para iniciar-se qualquer busca, os quais, no entanto, não excluem o critério mais abrangente da ética.

Se a questão da reprodução indiscriminada de textos constitui há muito uma prática comum, especialmente nos meios acadêmicos, o que se pode constatar sem equívoco, é a facilidade com que essa prática se generalizou a partir de utilização da Internet, em que pese o acesso restrito a determinados documentos, a existência de bases de dados por assinatura, e portanto a exigência de senha em muitos casos.

Por outro lado, muitos dos textos que são colocados diretamente na rede, e na íntegra, incluem cláusula de permissão de reprodução, desde que citada a fonte. Há também a situação um tanto paradoxal do texto que, embora acessado diretamente na rede, contém proibição de cópia sem o consentimento expresso do autor, independentemente da citação completa da fonte. 
O que se torna claro é que mesmo com a existência de todos os mecanismos que visam a preservar tanto o direito autoral como a exclusividade ou seletividade do acesso a determinados conteúdos, a Internet facilitou não só a cópia no sentido físico do termo, como o próprio plágio de idéias, criações e elaboração intelectual. Diante disso, não é de surpreender a dimensão que a questão da propriedade intelectual tem assumido nos últimos anos, tanto como objeto de legislação como de discussão contínua, na medida em que se pretende democratizar o conhecimento, por um lado, e coibir a fraude, por outro. A esse propósito, parece pertinente citar o relatório divulgado pela Association of Internet Researchers (ESS, 2002), no qual consta uma série de recomendações baseadas em perguntas práticas e estudos de caso. Nele são comparadas algumas abordagens adotadas por diferentes países e é apresentada uma relação de fontes e recursos eletrônicos sobre o assunto. Nesse, como em tantos outros documentos, procura-se, em última análise, situar a ética como critério indispensável na pesquisa eletrônica.

\section{O PROFISSIONAL DA INFORMAÇÃO E}

\section{A INTERNET}

"Como encontraremos informação numa Internet contendo 50 bilhões de registros, e na qual o maior dos índices não atinge mais que três ou quatro bilhões des- ses registros em seu total?" Essa indagação, feita por Novak (2003, p.4), motivada pela convicção de que há uma tendência de volta ao caos, a continuar o crescimento desproporcional da rede em relação ao dos motores de busca, ilustra bem o que significa encontrar-se a informação diante da complexidade do aparato tecnológico envolvido na inclusão de todos os assuntos existentes.

De acordo com esse autor, a Internet cresceu e ganhou peso, entrando em nova fase, razão pela qual uma única pessoa, por exemplo, não tem condições de organizar um guia completo de todos os recursos referentes a agricultura.

O que se constata, talvez como decorrência dessa realidade, é a proliferação de guias eletrônicos e orientações, que não só procuram tirar o melhor proveito da Internet como instrumento de pesquisa, como também atentam para as especificidades desse meio que, ao abrigar informações temporárias e voláteis, exige, por outro lado, uma série de habilidades como objetividade, seletividade, abertura intelectual, capacidade de decisão e flexibilidade por parte de quem busca conhecer algo específico em sua área de interesse, ou mesmo acompanhar a evolução de um determinado assunto enquanto foco de ação política ou estratégica.

Nessa perspectiva, torna-se relevante a atuação do profissional da informação 
em seu múltiplo papel de bibliotecário especializado, arquiteto da informação, organizador/provedor de conteúdos, gerente de recursos informacionais, e muitas outras atribuições que têm surgido em anos recentes, justamente como conseqüência da complexidade crescente da atividade de pesquisa na Internet. A esse propósito, cabe uma referência à palestra proferida por Nicholas Cop, da OCLC, em outubro de 2004, intitulada "Cenários para a sobrevivência da biblioteca". Diz ele que os quatro princípios básicos da referência digital são: interagir; cooperar; construir; gerenciar (COP, 2004).

A interação com o usuário (aquele que busca a informação) se dá de forma inédita, em termos de sincronia, rapidez, recurso a múltiplas fontes localizadas em pontos diferentes, atuação em redes e tudo isso graças à utilização das novas tecnologias da comunicação. A cooperação envolve desde o compartilhamento de aplicativos ao encaminhamento de perguntas não respondidas.

A construção implica a criação de recursos próprios, produtos e serviços, com base numa prospecção ambiental que leve em conta o contexto. Já o gerenciamento envolve, entre outros aspectos, a otimização de todos os recursos existentes em função dos múltiplos desafios enfrentados pelas bibliotecas diante da superabundância de informação na Internet e das necessidades reais de quem busca encontrar a informação que the interessa.

Ao apontar tendências da informação e de seus formatos para o período 20042009, Cop (2004) observa que o formato passa a ter menor importância que o conteúdo, e que o novo desafio é a "busca contextual."

\section{RECURSOS ACESSADOS}

Apenas a título de exemplificação, é apresentada a seguir uma pequena amostra das páginas acessadas aleatoriamente a partir de um levantamento no Google sobre o tema "pesquisa na Internet", realizado entre 2006 e os primeiros meses de 2007. O levantamento - obtido a partir de termos de busca em português, inglês e francês, e que produziu resultados na casa dos milhões - revelou uma predominância de guias elaborados e disponibilizados por universidades, como um reflexo, talvez, das prioridades da pesquisa acadêmica em relação a outros tipos de pesquisa. Alguns resultados, por outro lado, constituem pontos de partida para determinados tipos de informação, ou instrumentos mais diretamente voltados à busca por assunto.

Evaluating Web Pages: Techniques to Apply \& Questions to Ask

http://www.lib.berkeley.edu/TeachingLib/Gu ides/Internet/Evaluate.html (acesso em novembro de 2006). Esse é um dos links contidos no sumário do guia eletrônico disponibilizado pela Universidade de Berkeley. 
Dentre os demais tópicos, incluem-se uma conceituação de Internet; aspectos a considerar antes de iniciar-se a pesquisa; estratégia de busca recomendada; especificação de ferramentas de busca.

\section{Internet Research}

http://www.secondsight2000.com/resources /internet_research.htm

(acesso em outubro de 2006). Disponibilizada pela World Association of Opinion and Marketing Research Professionals, a página, que se refere basicamente a pesquisa de mercado, contém um link voltado a orientações para pesquisa na Internet.

\section{Subject Guides to Library and Internet} Resources

http://www.unf.edu/library/guides/subjectgui des.html (acesso em outubro de 2006) Guias por assunto referentes a recursos de biblioteca e Internet, disponibilizado pela biblioteca Thomas G. Carpenter, da Universidade do Norte da Flórida.

Bibliography of Internet Research Related Articles

http://basil.acs.bolton.ac.uk/ ch5/research/i nternet/netres_refs.htm

(acesso em agosto de 2006). Extensa bibliografia subdividida em diferentes tópicos, com predominância na área de Psicologia. Embora nem todos os títulos estejam disponíveis on-line, a relação é bastante ilustrativa quanto aos métodos e às diferentes aplicações da pesquisa eletrônica.

JournalismNet. The Investigative Guide to Internet Research

http://www.journalismnet.com/ (acesso em dezembro de 2006)

Colocado pelo Google na relação dos cinco primeiros sites de jornalismo do mundo, contém notícias e links para motores de busca. Requer senha para alguns de seus recursos.

Internet Research. From Wikipedia, the Free Encyclopedia

http://en.wikipedia.org/wiki/Internet_researc $h$ (acesso em fevereiro de 2007)

Artigo da Wikipedia sobre a utilização da Internet em pesquisa. Compreende uma definição do que constitui pesquisa na Internet, e tópicos referentes a credibilidade e ética, entre outros.

Uma Breve Introdução ao Uso dos Recursos Disponíveis na Rede http://eduardogalhardo.sites.uol.com.br/ (acesso em março de 2007)

Páginas organizadas e disponibilizadas pelo Professor Eduardo Galhardo, do Instituto de Biologia da USP (IBUSP), contendo "informações sobre a utilização da Internet na educação".

\section{Internet como Instrumento de Pesquisa} Técnico-Científica na Engenharia Civil http://www.ced.ufsc.br/ ursula/papers/civil_ net.html (acesso em abril de 2007)

Artigo de Ursula Blattmann e Ana Maria Delazari Tristão, situando a Internet como instrumento de pesquisa eletrônica na área de engenharia civil.

Conforme dito, essa é apenas uma pequena amostra de toda a imensa quantidade de páginas encontradas referentes à pesquisa na Internet. Outras páginas serão mais úteis ou objetivas, conforme o caso, para as diferentes e subjetivas necessidades de informação. Em muitos casos, porém, elas não são sequer consultadas, já que sua própria existência não deixa de traduzir, de certo modo, a complexidade inerente à busca da informação na rede, na medida em que o "mar está cada vez mais revolto" e o navegador não pode se perder...

\section{CONCLUSÃO}

A Internet constitui, sem dúvida, o maior instrumento de informação da atualidade. Graças à sua utilização, é possível 
em fração de segundos saber o que se passa em qualquer parte do mundo, obter notícias em tempo real, conhecer e interagir com pessoas em locais distantes, obter informações pontuais sobre a meteorologia e o câmbio, para citar somente alguns exemplos mais cotidianos.

No que se refere à pesquisa, seja ela acadêmica ou de outra natureza, as formas de buscar, e sobretudo de se encontrar a informação, apresentam algumas dificuldades, na medida em que diariamente são incluídas/excluídas/modificadas grandes massas de dados e informações na rede. Embora no intuito de facilitar o trabalho do pesquisador, a disponibilização de um grande número de guias de pesquisa eletrônica, reflete o problema.

Observa-se também que, a par de tais guias, há um trabalho contínuo de organização de informações por assunto, de modo a facilitar o acesso direto a conteúdos por área de interesse, seja a partir dos grandes motores de busca (Google, Yahoo), seja a partir de bases de dados, de pacotes organizados a pedido, grupos de discussão, informativos eletrônicos, e outros produtos e serviços criados para atender necessidades específicas. Nesse contexto, a questão da ética torna-se particularmente relevante, dada a facilidade de reprodução de documentos propiciada pela rede, e ao mesmo tempo, a necessidade da utilização justa e correta dos conteúdos acessados.
A Internet por si só não coloca automaticamente toda a informação existente no mundo ao alcance de todos. Uma certa tendência - já ultrapassada, diga-se de passagem - a se considerar o documento impresso (especialmente o livro) como algo obsoleto em função da magia do computador parece ter dado lugar a uma percepção equivocada quanto à facilidade do acesso à informação, acesso esse isento de quaisquer obstáculos (éticos, políticos, comerciais, tecnológicos, culturais). Tal facilidade tornaria injustificada, em princípio, a existência de bibliotecas, e dispensável a assistência de profissionais especializados, que ao tornarem mais curto e confiável o caminho que vai da pergunta (ou dúvida) à resposta (ou solução de um problema), agregam valor à informação obtida. A realidade tem demonstrado exatamente o contrário, na medida em que aos avanços tecnológicos têm correspondido novas demandas de informação, não só em termos da quantidade, mas principalmente quanto à qualidade, e é nesse aspecto que o profissional da informação - seja nas bibliotecas, em centros de pesquisa e documentação, e nos mais diversos ambientes de trabalho - passa a ter seu campo de atuação consideravelmente ampliado. 


\section{REFERÊNCIAS}

COP, Nicholas. Cenários para a Sobrevivência da Biblioteca. Palestra proferida em 26 de outubro de 2004 no Interlegis, auditório do Senado Federal, Brasília, DF. Baseada no relatório da OCLC de 2003.

EPPLER, Martin J.; MENGIS, Jeanne. The Concept of Information Overload: A Review of Literature from Organization Science, Accounting, Marketing, MIS, and Related Disciplines. The Information Society: An International Journal, Bloomington, v.20, n.5, p.325-344, 2004.

ESS, Charles; AoIR ethics working committee. Ethical decision-making and Internet resarch: Recommendations from the aoir ethics working committee. Approved by the AolR, November 27, 2002. Disponível em: $<$ http://www.aoir.org/reports/ethics.pdf>. Acesso em: jan. 2007.

NOVAK, David. Evolution of Internet Research: Shifting Allegiances. Research Commentary. The Spire Project. 2003. Disponível em: Disponível em:

$<$ <ttp://spireproject.com/art19.htm>. Acesso em: out. 2006.

\section{Dulce Baptista}

Licenciada em Letras (PUC-Rio). Bacharel em Biblioteconomia. Mestre em Educação e Doutora em Ciência da Informação (UnB).

Professora Adjunta do Departamento de Ciência da Informação e Documentação (UnB) dmbp@unb.br

\section{Title}

The use of Internet as an indispensable tool within contemporary information search: some relevant aspects

\section{Abstract}

Considering the internet as a revolutionary resource within the context of today's globalized world, this paper explores its usage as an indispensable tool in information search for research purposes, be it academic, scientific, practical, individual, commercial, political or other. The differences between search and research are analyzed, having as reference a study about the evolutionary process that took place within the web itself and within search engines. Ethics is regarded as a research criterion, having in view how easy it became to access, download and copy all kinds of documents from the web. Also described is the role of librarians as information professionals, vis a vis the new challenges brought about by technology and information explosion.

\section{Key words}

Internet; Globalization; Internet research; Internet seeking; Ethics; Information professional

\section{Título}

La utilización de la Internet como instrumento indispensable en la búsqueda contemporánea de la información: algunos aspectos relevantes

\section{Resumen}

A partir de la contextualización de la internet como recurso revolucionario en el mundo globalizado de hoy, el presente artículo explora su utilización como instrumento indispensable en la búsqueda de la información destinada a la investigación, sea para fines académicos, científicos, prácticos, individuales, comerciales, políticos, u otros. Se analiza la distinción entre diferentes tipos de búsqueda, con base en el estudio sobre la evolución de la red y de los motores de búsqueda. Se considera la ética como criterio de búsqueda., llevando a cabo la facilidad de acceso, de bajar y de reproducir 
los documentos mais variados a partir de la red. Se focaliza también el papel del bibliotecário como profesional de la información, frente a los desafíos aportados por la tecnología y por la explosión de la información.

\section{Palabras Clave}

Internet; Globalización; Búsqueda en la internet; Ética; Profesional de la información

Recebido em: 30.04.2007

Aceito em: 06.06.2007 